\title{
FORMULATION AND EVALUATION OF RELEASE OF TRIMETAZIDINE DIHYDROCHLORIDE HPMC MATRIX TABLET
}

\author{
*M Rajavar dhan Reddy, G Srikanth, B Mahendar, \\ Department of Pharmaceutical Analy sis, Pratishta Institute of Pharmaceutical Sciences, Durajpally, Sury apet, A.P., India-508214 \\ *Corresponding Author's Email: rajavardhanmodugulu@gmail.com
}

Received 29 May 2012; Review Completed 05 June 2012; Accepted 02 July 2012, Available online 15 July 2012

\begin{abstract}
ABS TRACT
Monolithic matrix tablets of Trimetazidine Dihydrochloride were formulated as modified release tablet employing hydroxyl propyl methyl cellulose polymer, and the modified release behaviour of fabricated tablets was investigated. Modified release matrix tablets contain $35.3 \mathrm{mg}$ Trimetazidine Dihydrochloride were developed using different drug polymer concentration of H.P.M.C. Tablets were prepared by wet granulation using I.P.A. Formulation was optimized on the basis of acceptable tablet properties and in vitro drug release. The resulting formulation produced robust tablets with optimum hardness, consistent weight uniformity and low friability. All tablets but one exhibited gradual and near-completion modified release for Trimetazidine Dihy drochloride, and 98.5 to $101.5 \%$ released at the end of $12 \mathrm{~h}$. The results of dissolution studies indicated that formulation FIII, the most successful of the study. An increase in release kinetics of the drug was observed on decreasing polymer concentration.

Key words: Trimetazidine Dihy drochloride, Modified release, Monolithic matrix tablets, hy droxyl propyl methyl cellulose polymer
\end{abstract}

\section{INTRODUCTION}

Trimetazidine Dihydrochloride is chemically described as $1-(2,3$, 4-trimethoxybenzyl) piperazine. It is an energy metabolism of the cell exposed to hypoxia or ischemic, avoids the collapse of the intracellular level of adenosine triphosphate (ATP). It thus ensures the functioning of the ion pumps and the transmembrane flow of sodiumpotassium and maintains cellular homeostasis. It has been used in the form of its Dihydrochloride as a coronary vasodilator for the prophylactic treatment of angina pectoris crisis, its short biological half life $(6 \mathrm{~h})$ that calls for frequent daily dosing ( 2 to 3 times) and therapeutic use in angina pectoris cris is disease necessitates its formulation into modified release dosage form ${ }^{1}$. The development of Modified / Controlled release formulation of Trimetazidine Dihydrochloride is therefore of therapeutic relevance and can be used to provide a consistent dosage through sustaining an appropriate level of drug over time. The simplest and least expensive way to control the release of the drug is to disperse it within an inert polymeric matrix and hydrophilic matrices are an interesting option when formulating an oral modified release (MR) of a drug. The dosage release properties of matrix devices may be dependent upon solubility of the drug in the polymer matrix or, in case of porous matrices, the solubility in the sink solution within the particle's pore network. Hydroxypropylmethylcellulose (HPMC) is the dominant hydrophilic vehicle used for the preparation of oral controlled drug delivery systems ${ }^{3}$. Numerous studied have been reported in literature investigating the HPMC matrices to control the release of a variety of drugs from matrices. The objective of the present study was to formulate Trimetazidine Dihydrochloride MR Matrix tablets using HPMC K4M polymer and to elucidate the release kinetics of Trimetazidine Dihydrochloride from HPMC matrices. We attempted a systematic approach to develop twice daily modified release Trimetazidine Dihydrochloride matrix tablets.

\section{MATERIALS AND METHODS}

Trimetazidine Dihydrochloride was obtained from MJ BIOPHARM Pvt ltd, Mumbai, HPMC K4M, a grade of HPMC, was procured from MJ BIOPHARM Pvt ltd, Mumbai, Dibasic Calcium Phosphate (Anhydrous), was procured from MJ BIOPHARM Pvt ltd, Mumbai., Polyvinyl Pyrrolidone (PVP-K30), Aerosil ${ }^{\mathrm{R}} 200$ and Magnesium Stearate, was procured from MJ BIOPHARM Pvt ltd, Mumbai, Isopropyl Alcohol was procured from Rankem, Delhi. Materials and excipients used in preparing tablets were IP grades. All other ingredients used throughout the study were of analytical grade and were used as received.

\section{Preparation of matrix tablets:}

Matrix tablets, each containing $35.3 \mathrm{mg}$ Trimetazidine Dihydrochloride, were prepared by wet granulation technique. The drug polymer concentration was developed to adjust drug release and to keep total weight of tablet constant for all the fabricated batches under experimental conditions of preparations. The total weight of the matrix tablets was $200 \mathrm{mg}$ with different drug polymer (HPMC) concentration. A batch of 1000 tablets was prepared in each formula. The composition of tablets is shown in Table 1. Dibasic calcium phosphate (anhydrous) was incorporated as filler excipient to maintain tablet weight constant. This filler was incorporated also for counterbalance the faster solubility of the drug in presence of hydrophilic polymer and to provide a stable monolithic matrix. The ingredients Trimetazidine Dihydrochloride, HPMC, Dibasic calcium phosphate (anhydrous) were passed through sieve no. 40 and mixed in a polybag. The powder blend was granulated using granulating fluid PVP- 
K30 dissolved in IPA and pass the wet mass through sieve no. 12. Dry the wet granules in a Tray dryer at $600^{\circ} \mathrm{c}$ for 1 hour. Pass the dried granules through sieve no. 20. The granules was then lubricated with magnesium stearate, Aerosil $^{\mathrm{R}} 200$ pass through sieve no. 40 and compressed into tablets on a 16-station single rotary Cadmach machine using $8.0 \mathrm{~mm} \mathrm{~S} / \mathrm{C}$ biconvex punches plain on both sides.

\section{Evaluation of tablets:}

The prepared matrix tablets were evaluated for hardness, weight variation, thickness, friability and drug content. Hardness of the tablets was tested using a strong-cobb hardness tester (Tab machine, Mumbai). Friability of the tablets was determined in a Roche friabilator (Campbell Electronics, Mumbai). The thickness of the tablets was measured by vernier callipers. Weight variation test was performed according to official method 9. Drug content for Trimetazidine Dihydrochloride was carried out by measuring the absorbance of samples at $231 \mathrm{~nm}$ using Shimad zu $1201 \mathrm{UV} / \mathrm{Vis}$ spectrophotometer and comparing the drug content from a calibrated curve prepared with standard Trimetazidine Dihydrochloride in the same medium

\section{In vitro drug release studies:}

The in vitro dissolution studied was carried out using USP 24 dis solution apparatus type II [10] (Basket method) at 50 rpm. Dissolution test was carried out for a total period of $12 \mathrm{~h}$ using $0.1 \mathrm{~N} \mathrm{HCl}(\mathrm{pH} 1.2)$ solution $(900 \mathrm{ml})$ as dissolution medium at $37 \pm 0.50$ for $1 \mathrm{hr}$, and $\mathrm{pH} 6.8$ phos phate buffer solution $(900 \mathrm{ml})$ minimu m of $2 \mathrm{hrs}$. Ten millilitres of the sample was withdrawn at regular intervals and replace with the same volume pre-warm $(37 \pm 0.50)$ fresh dissolution medium. The samples withdrawn were filtered through $0.45 \mu$ me mbrane filter, and drug content in each sample was analyzed after suitable dilution by abovementioned spectrophotometer at $231 \mathrm{~nm}$. The actual content in samples was read from a calibration curve prepared with standard Trimetazid ine Dihydrochloride.

\section{Stability studies:}

One selected fabricated tablet batch was strip packaged and kept at $400^{\circ} \mathrm{c}$ with $75 \%$ RH. Samples were withdrawn at 30 and $60{ }^{\circ} \mathrm{c}$ for evaluation of appearance, drug content and in vitro drug release.

\section{RES ULT AND DISCUSSION}

The result of hardness and friability of the prepared matrix tablets ranged from 7.0 to 8.5 and 0.12 to 0.31 respectively. (Table 3 ). The tablet formulations in all the prepared batches contained Trimetazidine Dihydrochloride within $100 \pm 5 \%$ of labelled content. As such, all the batches of the fabricated tablets were of good quality with regard to hardness, friability and drug content. All tablets complied with pharmacopoeial specifications for weight variation and friability. Trimetazidine Dihydrochloride release from tablets was slow and extended over longer periods of time. The results of dissolution studies of formulations F-I to F-V are shown in fig. 1. Drug release from the matrix tablets was found to increase with decrease in drug polymer concentration. Formulation F-I and F-II composed of drug concentration release to sustained release after $12 \mathrm{~h}$.

Table 1: Formulae of Trimetazidine Dihydrochloride tablet

\begin{tabular}{|c|c|c|c|c|c|}
\hline \multirow{2}{*}{ Ingredients $(\mathbf{m g} / \mathbf{t a b})$} & \multicolumn{4}{|c|}{ For mulations } \\
\cline { 2 - 6 } & $\mathrm{F}-1$ & $\mathrm{~F}-2$ & $\mathrm{~F}-3$ & $\mathrm{~F}-4$ & $\mathrm{~F}-5$ \\
\hline Trimetazidine Dihydrochloride & 36.4 & 36.4 & 36.4 & 36.4 & 36.4 \\
\hline HPMCK4M & 122 & 117 & 113 & 107 & 103 \\
\hline Di-basicCalcium Phosphate (anhyd) & 33 & 39 & 44 & 48 & 55 \\
\hline PVPK30 & 5 & 5 & 5 & 5 & 5 \\
\hline Aerosil & 1 & 1 & 1 & 1 & 1 \\
\hline Magnesium Stearate & 6.1 & 6.1 & 6.1 & 6.1 & 6.1 \\
\hline CPA & qs & qs & qs & qs & qs \\
\hline Total & 200 & 200 & 200 & 200 & 200 \\
\hline
\end{tabular}

The release of drug depends not only on the nature of matrix but also the drug polymer concentration. As the percentage of polymer increased, the kinetics of release decreased. This may be due to structural reorganization of hydrophilic HPMC polymer. Increase in concentration of HPMC may result in increase in the tortuosity or gel strength of the polymer. When HPMC poly mer is exposed to aqueous medium, it undergoes rapid hydration and chain relaxation to form viscous gelatinous layer (gel layer). Failure to generate a uniform and coherent gel may cause slow drug release [11, 12]. In vitro release studies demonstrated that the release of Trimetazidine Dihydrochloride from all these formulated MR matrix tablets can generally be modified (fig. 1). According to commercial tablet, modified release profile of oral controlled release formulation of Trimetazidine Dihydrochloride should provide a release of $25-45 \%$ in 1 $\mathrm{h}, 43-63 \%$ in $2 \mathrm{~h}$, NLT $60 \%$ in $4 \mathrm{~h}$ and NLT $80 \%$ in $8 \mathrm{~h}$. Formulation F-III tablet gave release profile close to the commercial modified release tablet needed for Trimetazidine Dihydrochloride (fig. 1). The data for stability studies carried out for F-III batch at $400^{\circ} \mathrm{c}$ with $75 \% \mathrm{RH}$ for $60 \mathrm{~d}$ revealed that no considerable differences in drug content and dissolution rate were observed (Table 4). It may be concluded from the present study that slow, controlled and complete release of Trimetazidine Dihydrochloride over a period of $12 \mathrm{~h}$ was obtained from matrix tablets (F-III). It is also evident from the results that formulation F-III is better system for twice-daily MR of Trimetazidine Dihydrochloride. 
Table 2: Percentage of drug release

\begin{tabular}{|c|l|l|l|l|l|l|l|}
\hline \multirow{2}{*}{ Formulation No } & \multicolumn{7}{|c|}{ PERCENTAGE OF RELEASE TN TIME (HRS) } \\
\cline { 2 - 8 } & $\mathbf{1 H r}$ & $\mathbf{2 H r}$ & $\mathbf{4 H r}$ & $\mathbf{6 H r}$ & $\mathbf{8 H r}$ & $\mathbf{1 0 H r}$ & $\mathbf{1 2 H r}$ \\
\hline F1 & 33.43 & 48.60 & 70.50 & 83.48 & 91.56 & 96.34 & 99.54 \\
\hline F2 & 35.34 & 49.12 & 72.34 & 86.41 & 92.66 & 97.37 & 99.65 \\
\hline F3 & 39.42 & 50.59 & 80.78 & 92.06 & 97.15 & 100.60 & 100.99 \\
\hline F4 & 40.41 & 51.53 & 81.92 & 91.31 & 96.54 & 97.82 & 99.92 \\
\hline F5 & 41.10 & 51.67 & 82.43 & 92.57 & 97.63 & 99.12 & 100.12 \\
\hline
\end{tabular}

Table 3: Properties of compressed Trimetazidine dihydrochloride Matrix tablet

\begin{tabular}{|c|c|c|c|c|c|}
\hline Formul ation & $\begin{array}{c}\text { Weight } \\
\text { (mg) }\end{array}$ & Hardness $\left(\mathrm{kg} / \mathrm{c}^{2}\right)$ & Thickness(mm) & Friabilit (\%) & $\begin{array}{c}\text { Drug } \\
\text { Content } \\
(\%)\end{array}$ \\
\hline F-1 & 200.1 & 6.0 & 3.7 & 0.31 & 99.54 \\
\hline F-2 & 198.4 & 5.0 & 3.6 & 0.22 & 99.65 \\
\hline F-3 & 202.0 & 8.2 & 3.1 & 0.18 & 100.99 \\
\hline $\mathrm{F}-4$ & 204.3 & 7.5 & 3.4 & 0.15 & 99.92 \\
\hline
\end{tabular}

Table 4: Stability studies of Formulated F-III batch tablet

\begin{tabular}{|c|c|l|l|}
\hline Parameter & Initial Tablets & \multicolumn{2}{|c|}{$\begin{array}{c}\text { Strip pack at 40 } \\
\text { with75\%RH }\end{array}$} \\
\hline \multirow{2}{*}{ Drug Content } & 100.99 & 30 days & 60 days \\
\cline { 3 - 4 } & & $99.67 \%$ & $99.55 \%$ \\
\hline
\end{tabular}

Note: Each value represents an average of two values

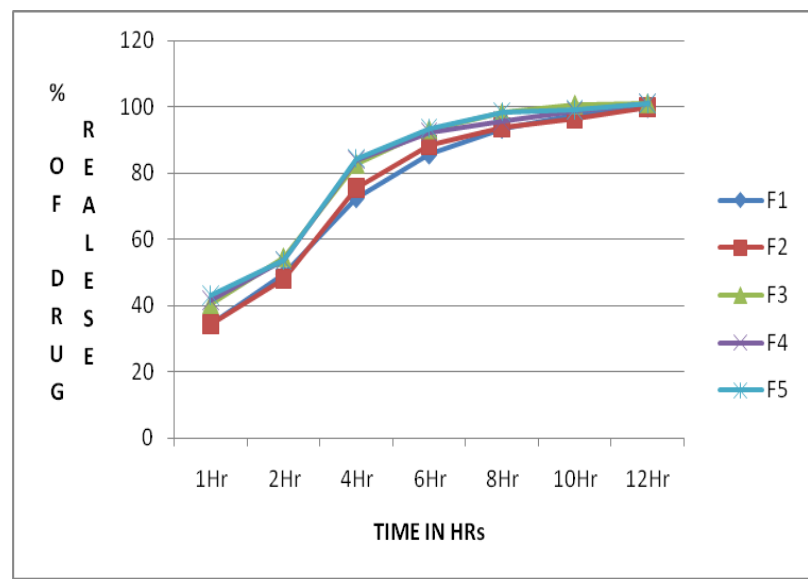

Figure 1: Percentage of drug release

\section{CONCLUSION}

In the above view of findings it can be concluded that the combination of hydrophobic polymer and $\mathrm{pH}$ dependent polymer are better suited for site specific drug delivery system than hydrophobic polymer alone. A matrix design of this kind can serve as an alternative strategy to enteric film coating techniques commonly employed for the design of delayed release systems.

\section{ACKNOWLEDGMENT}

The authors are thankful to Themis Pharmacueticals Ltd, Hyderabad for providing gift samples of Indomethacin, Evonik Degussa, Mumbai Colorcon, Goa, and ResearchLab Fine Chem Industries, Mumbai for providing gift samples of Cellu lose acetate phthalate and Ethyl cellulose respectively.

\section{REFERENCES}

1. Adir et Companies, Australian Patent No. 9403434 (1995).

2. Sing P, Desai SJ, Dimonelli AP, Higuchi WI, J. Pharm Sci., 1968, 57, 217.

3. Colombo P. Adv. Drug Deliv. Rev., 1993, 11, 37.

4. Chattaraj SC, Das SK, Drug Develop. Ind. Pharm., 1996, 22, 555.

5. Pabon CY, Frutos P, Lastres JL, Frutos G, Drug Develop. Ind Pharm., 1992, 18, 2163.

6. Lee BJ, Rayu, S.G. and Cui, J.H., Drug Develop. Ind Pharm., 1999, 25, 493.

7. Basak SC., Srinivasa Rao Y., Manavalan R. and Rama Rao P., Indian J. Pharm Sci., 2004, 66,827.

8. Basak SC, Srinivasa Rao Y., Manavalan R. and Rama Rao P., Indian J. Pharm Sci., 2004, 3, 61.

9. Indian Pharmacopoeia, Vol. II, 4 th Edn. The Controller of Publications, New Delhi, 1996, 736.

10. The United States Pharmacopoeia 24, The United States Pharmacopoeial Convention, Rockville, MD, 2000, 1942.

11. Sumathi S, Ray AR, J. Pharm. Pharmaceut. Sci., 2002, 5, 12.

12. Rajabi-Saibhoomi AR, Malia CD, Davies P, J. Pharm. Pharmacol., 1992, 44, 1062 